BENTHAM OPEN
CrossMark
Content list available at: www.benthamopen.com/TOEFJ/
DOI: $10.2174 / 1876973 \times 01609010055$

RESEARCH ARTICLE

\title{
The Study of Effect of Pore Structure on Oil Displacement Efficiency of Polymer Flooding
}

\author{
Ma Wenguo*
}

Key Laboratory of Enhancing Oil and Gas Recovery of Education Ministry, Northeast Petroleum University, Daqing, 163318, China

\begin{abstract}
Characteristics of pore structure have an important influence on the development of water flooding. In order to improve the recovery rate, it is important to investigate the relationship between pore structure and oil displacement efficiency. The permeability of the artificial cores in this experiment is $189 \times 10^{-3} \mu \mathrm{m}^{2}, 741 \times 10^{-3} \mathrm{~mm}^{2}$ and $21417 \times 10^{-3} \mu \mathrm{m}^{2}$. We used the CT technology method to scan the pore structure of the three cores, and did oil displacement experiment to investigate the effect of pore structure on the oil displacement efficiency. The result shows that the pore and throat common affect oil displacement efficiency: the bigger the pore and throat radius, the better is the oil displacement efficiency; the smaller the pore and throat radius, the worse is the oil displacement efficiency. The experiment studied the influence of pore structure on oil displacement efficiency deep into microcosmic pore structure without damaging the core skeleton, thereby improving the basis of oil recovery from the micro level and the mechanism.
\end{abstract}

Keywords: CT technology method, Oil displacement efficiency, Polymer flooding, Pore structure.

\section{INTRODUCTION}

Petroleum is a non-renewable resource. With the increase of the world oil consumption, new oil geological reserves are becoming scarce, and the exploitation of oil quality is becoming worse. To enhance the oil recovery has become a major task of the research of oil exploitation [1,2]. Oil that exists in reservoir space is formed by different types of pores, so the microscopic microcosmic pore structure of cores of the reservoir plays an important role in the recovery rate. Most of the previous research on the influence factors of oil displacement efficiency utilized geological conditions and development conditions [3 - 5]. As the study of geological conditions is often limited to the macro level, the block of similar geological conditions and development conditions, the oil displacement mechanism of different chemical ways on the same pore size level and different pore size levels at the same chemical way cannot explain the effective pore size range of polymer flooding, hence the cost of chemicals increases [6 - 9]. The limitations of the research bring difficulties to the study on mechanism and the prediction of polymer flooding, and also impact the scientific establishment for the polymer flooding development planning [10].

Characteristics of microcosmic pore structure of cores are the main factors influencing reservoir capability and oil and gas resources. Therefore, the characteristics of microcosmic pore structure of cores of rock clearly play a key role in improving the productivity of oil and gas reservoir and oil and gas recovery [11 - 13]. The description method of characteristics of microcosmic pore structure of cores includes: laboratory experiments and field well logging evaluation. The indoor experiment method is the main method, at present, also the most widely used to describe and evaluate the microcosmic pore structure of cores, which mainly includes: the capillary pressure curve method (the high pressure semi permeable membrane, mercury intrusion and centrifuge method, etc.), thin section method, scanning

\footnotetext{
* Address correspondence to this author at the Northeast Petroleum University, No. 199 Fa Zhan Road, High-Tech district, DaQing, Heilongjiang Province, China; Tel: +8613946947225; Fax:+864596803482; E-mail: mawenguo110@163.com
} 
electron microscope and CT scanning method. CT scanning method is the most direct and accurate method for the establishment of microcosmic pore structure of cores. With the rapid development of CT technology, high spatial resolution and accuracy of microcosmic pore structure of cores can be achieved [14 - 17]. The current study investigated the relationship between the oil displacement effect from the reservoir microscopic pore structure of cores and polymer deep into micro level, revealing the inner link of porous media and oil displacement effect at the micro level [18 - 21]. The result may imply that the influence of microcosmic pore structure of cores on the oil displacement efficiency of polymer flooding is still significant under the condition of big microcosmic pore structure of cores.

\section{BASIC PRINCIPLES OF CT SCANNING}

An X-ray (radiography) system produces two-dimensional shadow images of complete internal three-dimensional structures, but in a single two-dimensional shadow projection the depth information is completely mixed. Only an X-ray tomography system allows us to visualize and measure complete three-dimensional object structures without sample preparation or chemical fixation. Typically, the spatial resolution of conventional medical CT-scanners is in the range of $1 \sim 2.5 \mathrm{~mm}$, which corresponds to $1 \sim 10$ cubic mm voxel (volume element) size. Computerized X-ray microscopy and micro tomography now give possibilities to improve the spatial resolution by seven to eight orders in terms of volume.

Any X-ray shadow image is corresponding to a two-dimensional projection from the three-dimensional object. Each point on the shadow image contains the integration of absorption information inside the three-dimensional object in the corresponding partial X-ray beam (Fig. 1).

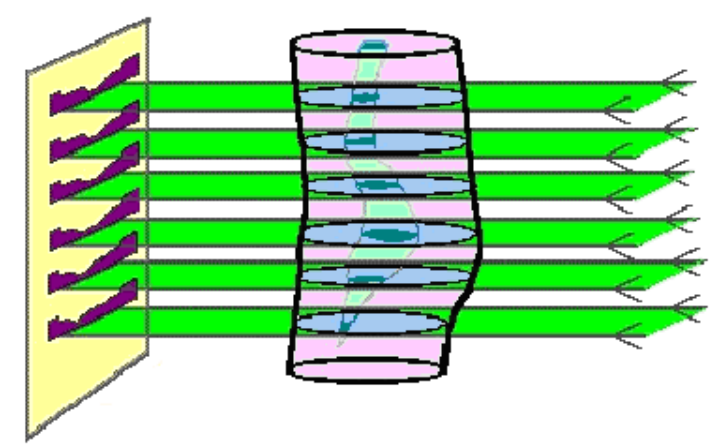

Fig. (1). Parallel beam geometry.

In this study, we used a point source which produces a cone X-ray beam in the object area. X-ray source is not able to generate parallel beams. For tomography reconstruction, the solution of this problem can be found by the reordering of the shadow information. In a fan beam geometry, the reconstructed slices will show some distortions far from the optical axis. In order to solve these errors, we have to use a 3D cone beam reconstruction algorithm (such as Feldkamp), in order to take into account the thickness of the object. In other words, the rays going through the front and the back of the object will not be projected on the same row of the detector. This is a non-linear operation which results in the fact that any noise in the small signal areas can produce significant errors in reconstruction. To eliminate these errors an averaging of initial data can be used. On the other hand, we can try to improve the signal to noise ratio in the shadow image by optimizing the exposure time in order to reach the most representative information (Fig. 2).

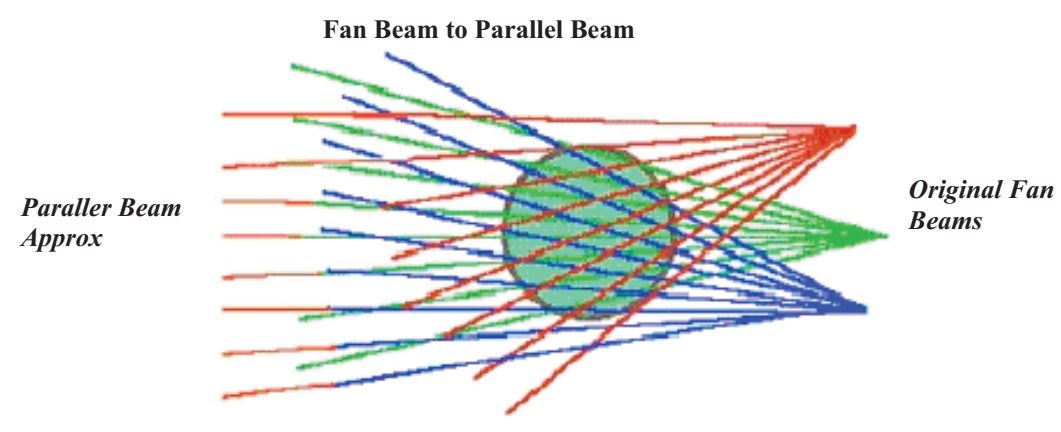

Fig. (2). Reordering the X-rays from fan beam to parallel beam. 
After reconstructing the raw data cross section, for 8 bit images 256 gray scales are used. Therefore, we have to convert the 16 bit information from the floating point matrix into a gray scale image. The minimum and maximum values are selected. All values between these will be displayed as half tone. In a normal image, all attenuation values below the minimum will be white, while everything above the maximum will be displayed as black. The reconstructed array will be shown as a half-tone image of the cross section with linear conversion to 256-grades of gray inside the selected density interval.

The following image summarizes all the actions and steps to generate the cross sectional data (Fig. 3):

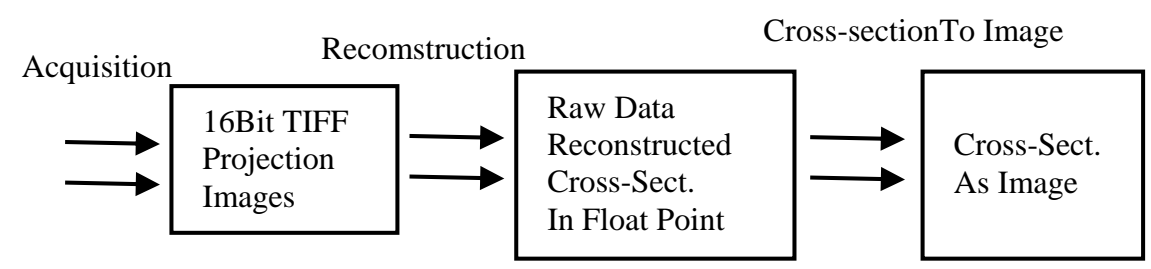

Fig. (3). Process of generating cross section data (Note: Rectify the spelling of reconstruction).

\section{MECHANISM OF POLYMER FLOODING}

Compared with other chemical flooding, polymer flooding is a relatively simple mechanism. The polymer can improve water/oil mobility ratio by increasing the viscosity of the injected water and reducing water permeability reservoir, adjust the injection profile, expand swept volume and enhance oil recovery.

Polymer flooding can improve the driving pressure difference inside the rock; the injected liquid can overcome capillary resistance in small pore and go into small pore for oil displacement. Its role is mainly manifested in three aspects: Firstly, the adsorption: When a large portion of polymer is adsorbed on the pore walls, it reduces the flow capacity of the water phase, least impacting the oil phase, and in the same oil saturation, relative permeability of the oil phase increases as compared to water flooding. Secondly, the viscous effects: Since the viscoelastic polymer reinforces viscous effect of irreducible oil of water, the irreducible oil flows again and entrains out with the polymer solution. Thirdly, increasing the driving pressure difference: polymer improves the driving pressure inside the rock, making the injected liquid overcome big capillary resistance in small holes and flood into the tiny pores [22, 23].

In general, the mechanism of polymer flooding is mainly displayed in: (1) Improving sweep efficiency of macro oil recovery efficiency. After the polymer formation, it will increase the viscosity of the injected water, reduce water permeability, adjust the oil injection profile, improve the plane heterogeneity, increase the thickness of washing, expand the swept volume of the aqueous phase and improve macroscopic sweep efficiency. (2) Increasing the microscopic oil displacement efficiency. Selecting the appropriate reservoir, correcting injection system design, polymer flooding can improve the recovery of $10 \%$. Domestic and foreign experts believe that this is due to the fact that polymer has viscoelastic effects at a certain injection speed so as to improve the oil displacement efficiency. Its main mechanism of displacement includes: (1) Viscoelastic polymer solution drags and carries irreducible oil on the blind side of the pore. (2) Polymer solution on continuous film carrying mechanism. (3) Viscoelastic polymer solution on irreducible oil of pore throats carrying mechanism. (4) Viscoelastic polymer solution on irreducible oil of traps carrying mechanism.

\section{EXPERIMENT}

\subsection{CT Scanning Experiment}

The experiment uses high frequency CT machine Sky-Scan 1172, as shown in Fig. (4). Test precision of the machine can reach 0.1 microns. The corresponding software includes: Data Viewer, CTAN, ANT and CT-Vol, rock cutting machine, artificial cores with permeability of $189 \times 10^{-3} \mu \mathrm{m}^{2}, 741 \times 10^{-3} \mu^{2}$, and $21417 \times 10^{-3} \mu \mathrm{m}^{2}$. 


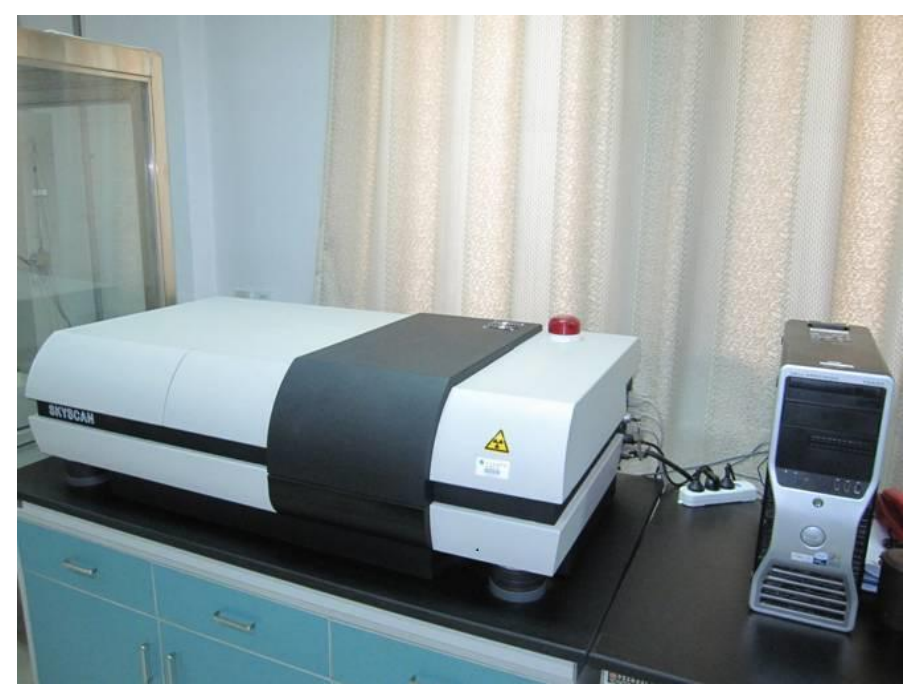

Fig. (4). Micro-CT machine (Sky-Scan 1172).

Experimental procedure:

1. Use machine to cut the core according to the size of CT holder requirements;

2. The experimental instrument is preheated for 15 minutes;

3. Through the observation of the sample position, adjust the appropriate position to start scanning;

4. Reconstruct the obtained data images into $2 \mathrm{D}$ cross section via the N-recon;

5. Analyze and calculate of the parameters of microcosmic pore structure of cores by using CTAN software;

6. Select the 30 50 layer for 3D reconstruction. Select appropriate gray value range. Reconstruct rock skeleton. Select inverse gray range and reconstruct rock pore;

7. The experimental data analysis and summary.

\subsection{Water Flooding Experiment}

The experiment saturated the cores with $6778 \mathrm{mg} / \mathrm{L}$ simulated water, and used $3700 \mathrm{mg} / \mathrm{L}$ simulated water in water flooding. The experimental oil is made up of the oil for Daqing oil factory dehydration of crude oil and aviation kerosene (Fig. 5). The viscosity of simulation oil is $9.8 \mathrm{cp}$ (Fig. 6). The experiment is at a constant temperature of $45^{\circ} \mathrm{C}$ in the laboratory.

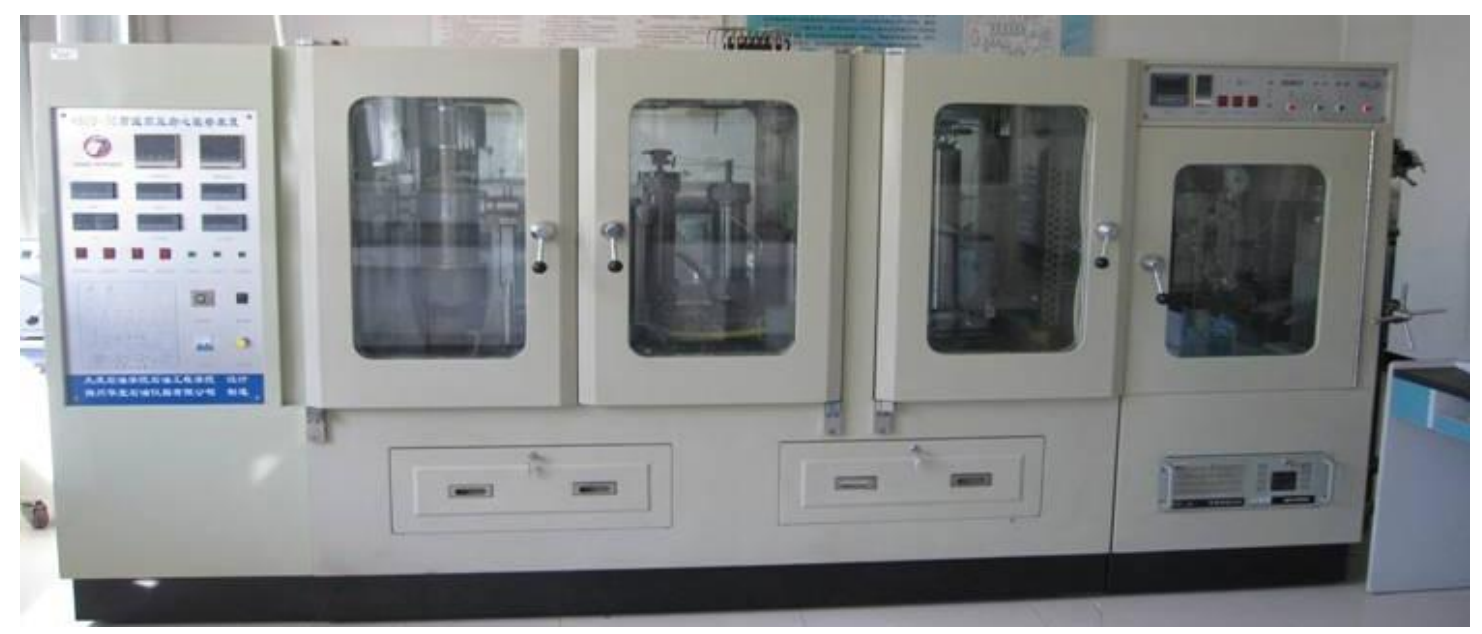

Fig. (5). The displacement equipment. 


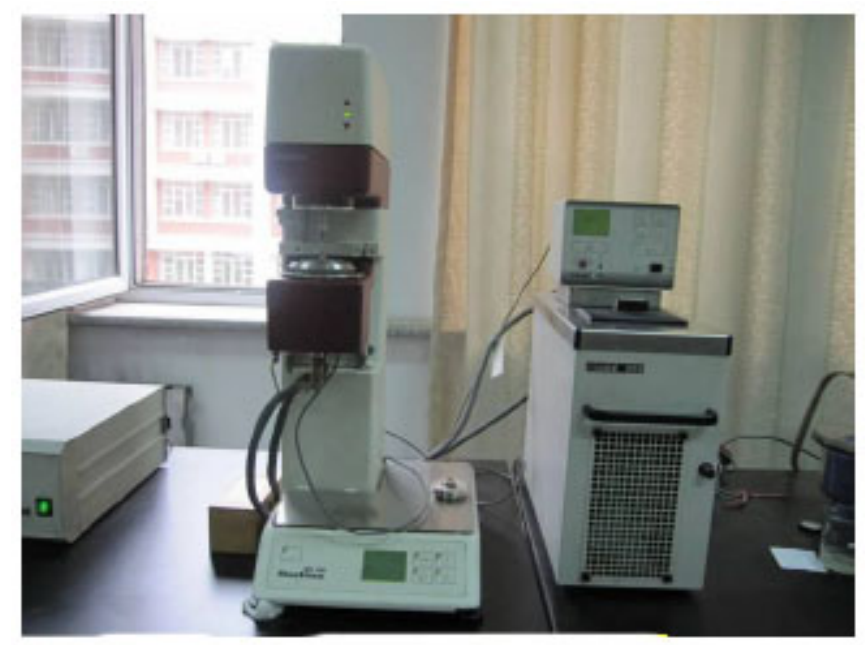

Fig. (6). Rheometer (HAAKE 150).

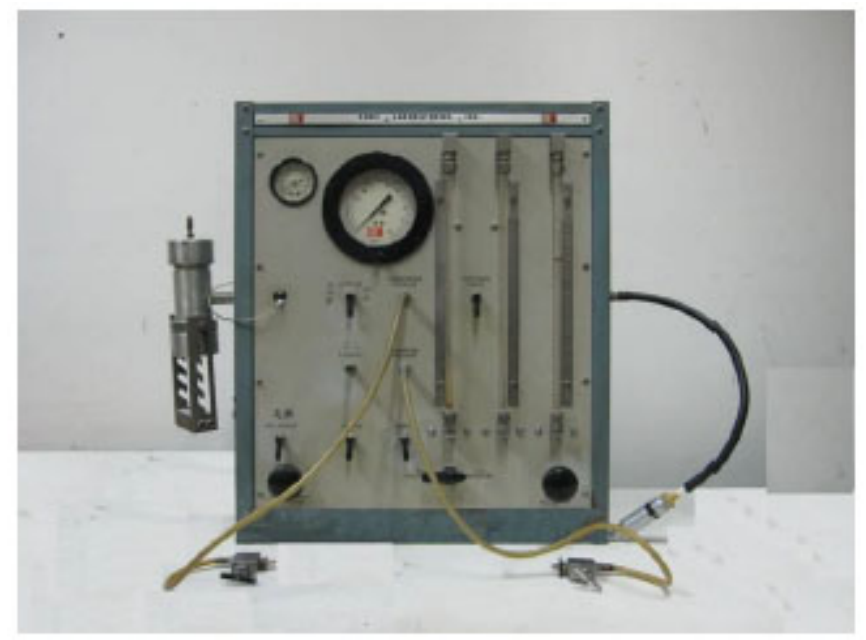

Fig. (7). Permeability tester.

Experimental procedure:

1. Check the ring pressure and make it constant at 4.0Mpa.

2. ISCO pump is connected to the middle container with simulation water, and exhausting. After they are connected to the core holder end of the valve, open the valve, and connect six-way pressure gauge to the other end of the core holder and open the valve on the six-gauge to exhaust.

3. U-shaped tube is connected with the core holder at the other end to the valve, opening the valve, ISCO pump flow is set to $0.1 \mathrm{ml} / \mathrm{min}$ injection.

4. Measure pressure, fluid withdrawal rate, oil production once every $10 \mathrm{~min}$.

5. Use the above data to calculate the cumulative oil production, recovery ratio and water ratio.

When the water content is $98 \%$, terminate water displacing.

The value of oil recovery efficiency at different flooding stages can be expressed as:

$$
E_{R}=1-\frac{S_{o r}}{S_{o i}}
$$

Thus, $S_{o r}$ is the residual oil saturation, and $S_{o i}$ is the original oil saturation. 


\subsection{Polymer Flooding Experiment}

Polymer solution was configured with $508 \mathrm{mg} / \mathrm{L}$ simulated water. Polymer solution used for the experiment was at the concentration of $1000 \mathrm{mg} / \mathrm{L}$, along with molecular weight of 25 million.

Experimental procedure:

1. After water displacing, close the six valves and intermediate container of water, open the connection valve and connect polymer intermediate container, and then initiate polymer flooding inject, $0.1 \mathrm{ml} / \mathrm{min}$, injection of $0.57 \mathrm{PV}$.

2. Measure pressure, fluid withdrawal rate, oil production once every $10 \mathrm{~min}$.

3. Use the above data to calculate the cumulative oil production, recovery ratio and water ratio. When the polymer injection amount is $0.57 \mathrm{PV}$, initiate subsequent water flooding, and when the water content is $98 \%$, terminate water displacing.

4. Calculate the value of oil recovery efficiency.

\section{RESULT AND ANALYSIS}

The experiment gets the distribution of pore radius, throat radius and pore-throat ratio of different permeability artificial core (Fig. 7).

Fig. (8) shows the histogram of pore radius distribution frequency: the cores with permeability of $189 \times 10^{-3} \mu \mathrm{m}^{2}$ and $741 \times 10^{-3} \mu \mathrm{m}^{2}$ have the pore radius distribution frequency mainly concentrated in $5.3 \mu \mathrm{m} \sim 7.5 \mu \mathrm{m}$ range. The pore radius of the core permeability of $21417 \times 10^{-3} \mu \mathrm{m}^{2}$ is still distributed part in the low value, but overall, the majority of pore radius is mainly distributed in the high range; the distribution frequency in $49.2 \mu \mathrm{m}$ is $32.7 \%$.

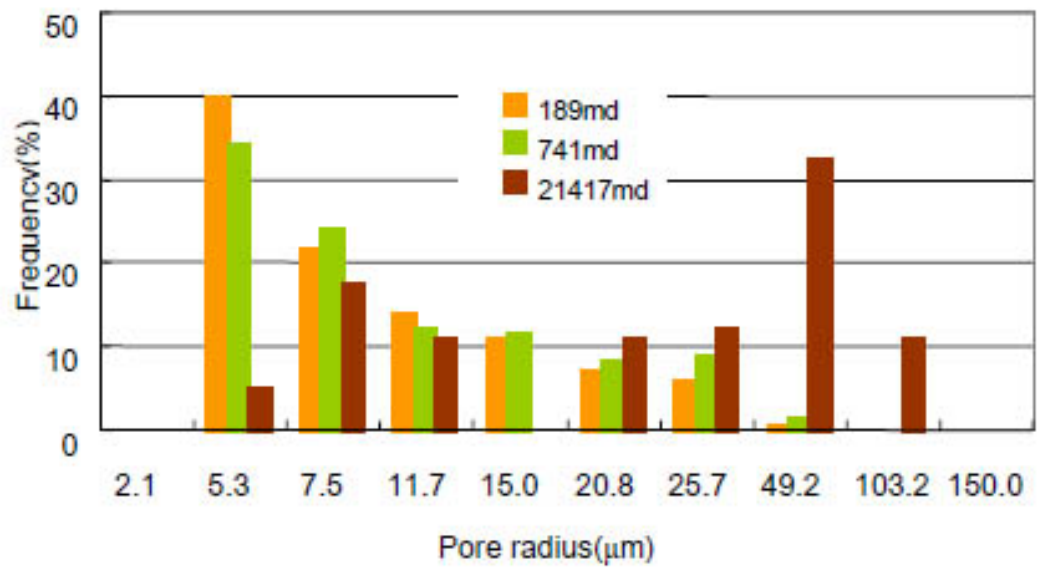

Fig. (8). Distribution frequency of pore radius.



Fig. (9). Distribution frequency of throat radius. 
Fig. (9) shows the histogram of throat radius distribution frequency: the cores with permeability of $189 \times 10^{-3} \mu \mathrm{m}^{2}$ and $741 \times 10^{-3} \mu \mathrm{m}^{2}$ have the throat radius distribution frequency mainly concentrated in $1.0 \mu \mathrm{m} \sim 2.5 \mu \mathrm{m}$ range; the throat radius of the core permeability of $21417 \times 10^{-3} \mu^{2}$ is mostly located in the high range.

Fig. (10) shows the histogram of pore-throat ratio distribution frequency: the cumulative distribution of values of the core pore-throat ratio with permeability $189 \times 10^{-3} \mu^{2}$ is $80.5 \%$ greater than value 3 . The cumulative distribution of values of the core pore-throat ratio with permeability $741 \times 10^{-3} \mu \mathrm{m}^{2}$ is $79.2 \%$ greater than value 3 . The cumulative distribution of values of the core pore-throat ratio with permeability $21417 \times 10^{-3} \mu \mathrm{m}^{2}$ is $77.8 \%$ greater than value 3 .

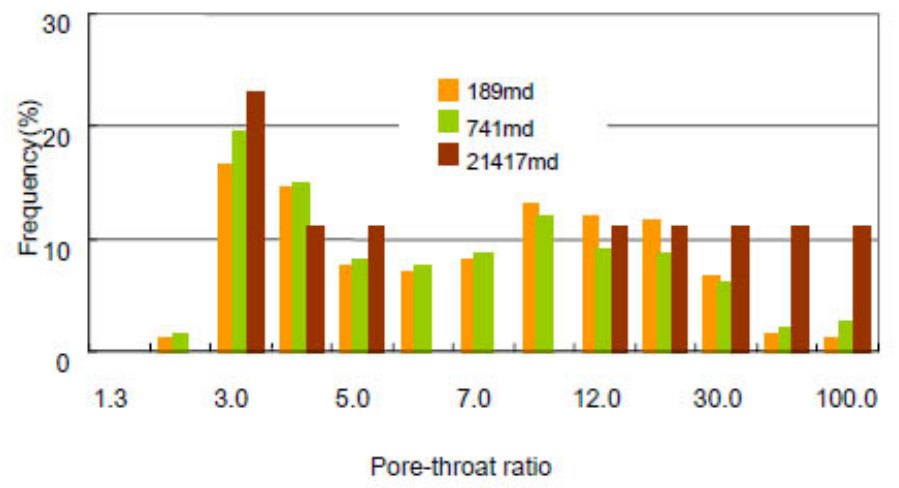

Fig. (10). Distribution frequency of pore-throat ratio.

After the experiments of vacuuming, water saturating, oil saturating, water oil displacement experiment was done on the three cores of different permeability. We measured pressure, fluid withdrawal rate, and oil production once every $10 \mathrm{~min}$ during water flooding stage, and used the above data to calculate the cumulative oil production, recovery ratio and water ratio. When the water content is $98 \%$, stop water flooding experiment and begin polymer flooding experiment (the molecular weight of 25 million, the concentration of $1000 \mathrm{mg} / \mathrm{L}$, and injection of $0.57 \mathrm{PV}$ ).

The recovery rates of water flooding and polymer flooding stage are shown in Fig. (6). At water flooding stage: the recovery rate of $189 \times 10^{-3} \mathrm{~mm}^{2}$ permeability core is $36.1 \%$; the recovery rate of $741 \times 10^{-3} \mu \mathrm{m}^{2}$ permeability core is $37.4 \%$; and the recovery rate of $21417 \times 10^{-3} \mu \mathrm{m}^{2}$ permeability core is $64.2 \%$.

Recent studies show that after viscoelastic fluid and viscous fluid displace core in the same condition, the residual oil saturation of the former is significantly lower than that of the latter. This shows that, viscoelastic polymer solution can not only improve the macroscopic sweep efficiency, but can also greatly improve the microscopic oil displacement efficiency. In the experiment, we determined the viscosity of the polymer solution, and the result of determination is shown in Figs. (11 and 12). Fig. (11) shows the experimental modulus curves of polymer solution. $\boldsymbol{G}^{\prime}$ is called the storage modulus and $\boldsymbol{G}^{\prime \prime}$ is called the loss modulus. For the viscous properties of polymer solution, part of the energy is dissipated or lost; and for the elastic properties, part of the energy is stored. The storage modulus ( $\left.\boldsymbol{G}^{\prime \prime}\right)$ reflects the elasticity of viscoelastic fluid, and the loss modulus $\left(\boldsymbol{G}^{\prime}\right)$ reflects the stickiness of viscoelastic fluid (Figs. 11 and $\mathbf{1 2}$ ).

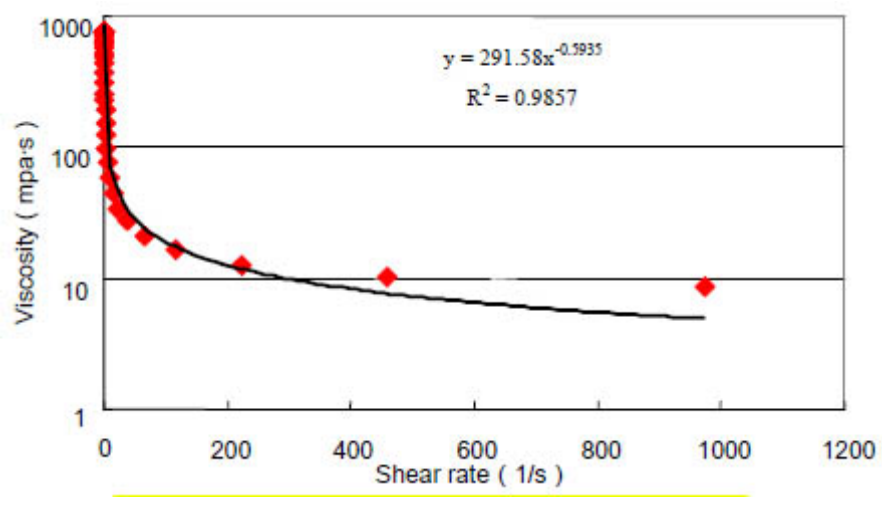

Fig. (11). Viscosity curve of the polymer solution. 


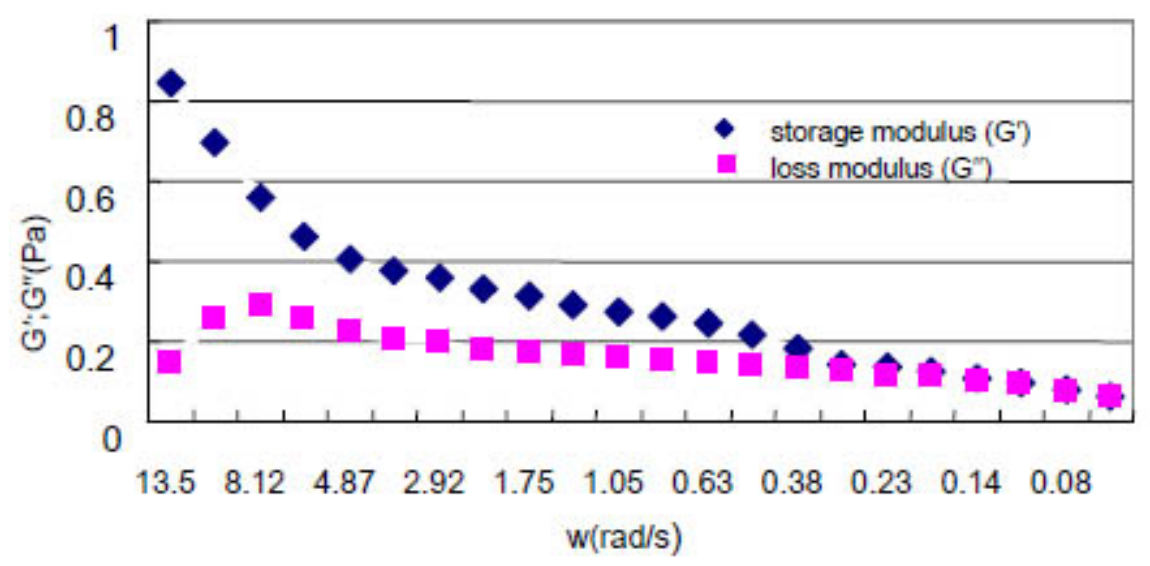

Fig. (12). Storage modulus and loss modulus curve of the polymer solution.

Polymer flooding stage: the recovery rate of $189 \times 10^{-3} \mu^{2}$ permeability core is $6.2 \%$; the recovery rate of 741 $\times 10^{-3} \mu \mathrm{m}^{2}$ permeability core is $7.9 \%$; and the recovery rate of $21417 \times 10^{-3} \mu \mathrm{m}^{2}$ permeability core is $9.8 \%$.

The result of the experiment shows that: the recovery rate increases with the increase of the average pore radius and throat radius, and this trend is more obvious in water displacement experiment (Fig. 13). At polymer concentration under the condition of $1000 \mathrm{mg} / \mathrm{L}$, the recovery rate also increases with the increase of the average pore radius and throat radius, but the trend is not obvious. In fact, oil saturation of the core with bigger pore and throat radius is already much lower than the other two cores at the water flooding stage. However, the polymer flooding recovery rate is still higher than the two low permeability cores. Therefore, relatively speaking, the increased recovery rate of high permeability core is higher than that of low permeability cores. The process of crude oil displacement in porous media is actually a process during which displacing fluid overcomes the capillary force. The bigger the pore radius, the lesser the capillary force, and more easily the displacing fluid overcomes the capillary force, thus validating that the recovery rate increases along with the pore and throat radii.

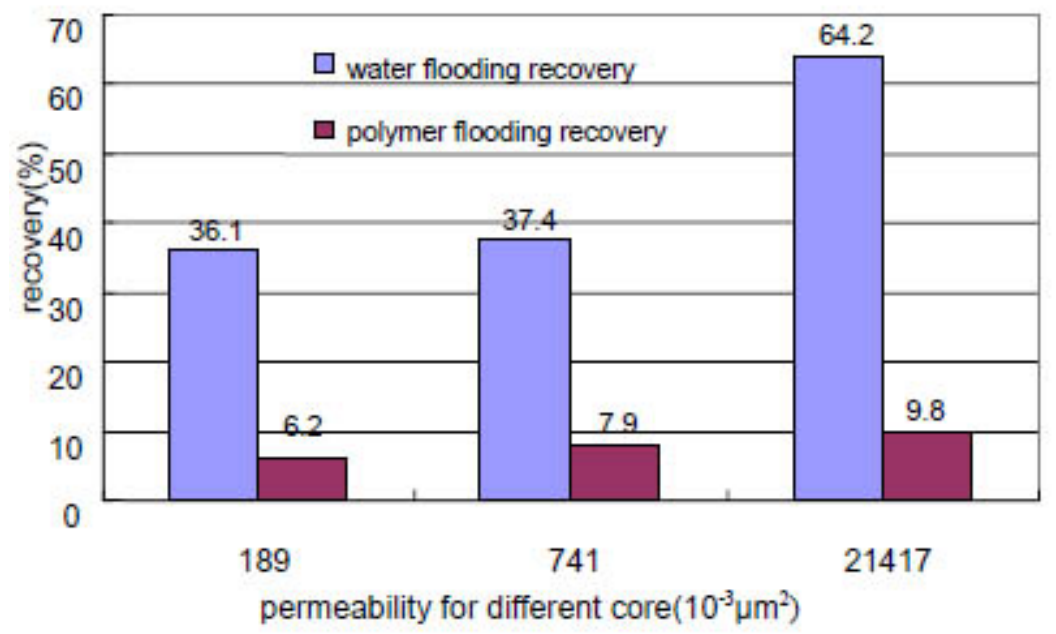

Fig. (13). The recovery rate of water flooding and polymer flooding stages.

\section{CONCLUSION}

In summary (permeability: $189 \times 10^{-3} \mu \mathrm{m}^{2} \sim 21417 \times 10^{-3} \mu \mathrm{m}^{2}$ ), pore and throat work together to control seepage ability. With the increase of permeability, pore radius increases and the distribution range becomes wider; pore radius also increases, but the increasing extent is less than the increase in the throat radius. The microcosmic pore structure of low permeability core is more complicated, so the distribution of pore-throat ratio is wide. With high permeability cores of $21417 \times 10^{-3} \mu^{2}$, the number of effective pores of the analysis area is little because of the large cemented sandstone 
particle and pore size.

The pore and throat radii influence the effect of water and polymer flooding together. The microcosmic pore structure of cores has great effect on oil recovery efficiency, the bigger the pore and throat radii, the better the significant effect of water flooding and polymer flooding. The oil recovery efficiency of three different corresponding permeability cores are respectively $36.1 \%, 37.4 \%$ and $64.2 \%$ at water flooding stage, and at polymer flooding stage, the $E_{R}$ of three high permeability cores are respectively $6.2 \%, 7.9 \%$ and $9.8 \%$.

This study only investigates the effect of microcosmic pore structure of core parameters of polymer flooding at the molecular weight in the same conditions. In fact, in order to achieve the ideal effect of polymer flooding, there should be one best matching relationship between reservoir microcosmic pore structure of cores and molecular weight of polymer. The pore radius distribution frequency of $189 \times 10^{-3} \mu^{2}$ and $741 \times 10^{-3} \mu \mathrm{m}^{2}$ is mainly concentrated in $5.3 \mu \mathrm{m} \sim 7.5 \mu \mathrm{m}$ range. The pore radius distribution frequency of $21417 \times 10^{-3} \mu \mathrm{m}^{2}$ is concentrated in $5.3 \mu \mathrm{m} \sim 103.2 \mu \mathrm{m}$ range, and the distribution frequency when pore radius is $49.2 \mu \mathrm{m}$ is $32.7 \%$. The result may imply that influence of microcosmic pore structure of cores on $E_{R}$ of polymer flooding is still significant under the condition of big microcosmic pore structure of cores. Therefore, we will continue to investigate how the matching relationship of the polymer and pore volume distribution influences the effect of polymer flooding recovery.

\section{CONFLICT OF INTEREST}

The authors confirm that this article content has no conflict of interest.

\section{ACKNOWLEDGEMENTS}

This research was financially supported by National Science and Technology Major Projects (Grant No. 2016ZX05010002-004 and 2016ZX05009003-010), Natural Science Foundation of China (project number: 51374076), and Education Department of Heilongjiang Province of China (key project: 12541z004).

\section{REFERENCES}

[1] Zhou, Y.C.; Wang, J.H.; Yuan, Y. The study of polymer flooding mechanism and influencing factors. Sci. Technol. Innov. Herald, 2011, 34, 65 .

[2] Zhu, Y.Y.; Hou, Q.F.; Jian, G.Q.; Ma, D.S.; Wang, Z. Current development and application of chemical combination flooding technique. Pet. Explor. Dev. Online, 2013, 1, 90-96.

[3] Iglauer, S.; Paluszny, A.; Blunt, M.J. Simultaneous oil recovery and residual gas storage: a pore-level analysis using in situ X-ray microtomography. Fuel, 2013, 103, 905-914.

[http://dx.doi.org/10.1016/j.fuel.2012.06.094]

[4] Ma, W.G.; Xia, H.F. The effect of rheological properties of alkali-surfactant- polymer solution on residual oil recovery rate after water flooding. Soc. Pet. Eng., 2010. SPE134064

[5] Chen, Y.L.; Ni, J.; Jiang, L.H.; Liu, M.L.; Wang, P.; Azzam, R. Experimental study on mechanical properties of granite after freeze-thaw cycling. Environ. Earth Sci., 2014, 71, 3349-3354. [http://dx.doi.org/10.1007/s12665-013-2725-0]

[6] Wang, J.; Liu, H.Q. A novel model and sensitivity analysis for viscoelastic polymer flooding in offshore oilfield. J. Ind. Eng. Chem., 2013, 2, 656-667.

[7] Gao, J.; Han, D.; Wang, J.L.; Wu, K.Y.; Liu, L. Application of CT scanning image technique to study of oil saturation distribution in core displacement test. Xinjiang Pet. Geol., 2009, 30(2), 269-271.

[8] Ma, W.G.; Wang, Y.; Hai, M.Y.; Xia, H.F.; Feng, H.C.; Wu, D. Research of microcosmic pore structure of cores characteristics of cores based on mercury penetration experiments. Exp. Technol. Manage., 2013, 30(1), 66-69.

[9] Xia, H.F.; Zhai, S.Q.; Feng, H.C.; Yin, D.Y.; Ma, W.G.; Wang, Y. Experimental research on pore and coordination number of cores based on CT scanning technique. Exp. Technol. Manage., 2013, 30(4), 20-23.

[10] Xia, H.F.; Wang, D.M.; Guan, Q.J.; Liu, Y.K. Viscoelastic polymer solution experiment. Daqing Inst. Pet., 2002, $26,106-107$.

[11] Wong, P.Z.; Koplik, J.; Tomanic, J. Conductivity and permeability of rocks. Phys. Rev. B, 1984, 30, 6606-6614. [http://dx.doi.org/10.1103/PhysRevB.30.6606]

[12] Rodriguez, S.; Romero, C.; Sargenti, M.L. Flow of polymer solutions through porous media. J. Non-Newt. Fluid Mech., 1993, 49, 63-85. [http://dx.doi.org/10.1016/0377-0257(93)85023-4]

[13] Gunde, A.C.; Bera, B.M.; Mitra, S.K. Investigation of water and $\mathrm{CO}_{2}$ (carbon dioxide) flooding using micro-CT (micro-computed tomography) images of Berea sandstone core using finite element simulations. Energy, 2010, 35(12), 5209-5216. [http://dx.doi.org/10.1016/j.energy.2010.07.045] 
[14] Yang, B.H.; Wu, A.X.; Miao, X.X.; Liu, J.Z. 3D characterization and analysis of microcosmic pore structure of cores of packed ore particle beds based on computed tomography images. Trans. Nonferrous Met Soc. China, 2014, 24(3), 833-838. [http://dx.doi.org/10.1016/S1003-6326(14)63131-9]

[15] Iglauer, S.; Favretto, S.; Spinelli, G.; Schena, G.; Blunt, M.J. X-ray tomography measurements of power-law cluster size distributions for the nonwetting phase in sandstones. Phys. Rev. E Stat. Nonlin. Soft Matter Phys., 2010, 82(5 Pt 2), 056315. [http://dx.doi.org/10.1103/PhysRevE.82.056315] [PMID: 21230584]

[16] Chiquet, P.; Broseta, D.; Thibeau, S. Wettability alteration of caprock minerals by carbon dioxide. Geofluids, 2007, 7(2), 112-122. [http://dx.doi.org/10.1111/j.1468-8123.2007.00168.x]

[17] Fusi, N.; Martinez, J. Mercury porosimetry as a tool for improving quality of micro-CT images in low porosity carbonate rocks. Eng. Geol., 2013, 166, 272-282.

[http://dx.doi.org/10.1016/j.enggeo.2013.10.002]

[18] Matsuoka, A.; Yoshino, T.; Kishimoto, N.; Ishida, N.; Kurihara, T.; Kimoto, K.; Matsuura, S. Exact number of pore frames and their configuration in the Mesozoic radiolarian Pantanellium: An application of X-ray micro-CT and layered manufacturing technology to micropaleontology. Mar. Micropaleontol., 2012, 88, 36-40.

[http://dx.doi.org/10.1016/j.marmicro.2012.02.005]

[19] Cnudde, V.; Cwirzen, A.; Masschaele, B.; Jacobs, P.J. Porosity and microstructure characterization of building stones and concretes. Eng. Geol., 2009, 103(3-4), 76-83.

[http://dx.doi.org/10.1016/j.enggeo.2008.06.014]

[20] Oren, P.E.; Pinczewski, W.V. Fluid distribution and pore-scale displacement mechanisms in drainage dominated three phase flow. Transp. Porous Media, 1995, 1, 105-133. [http://dx.doi.org/10.1007/BF00616927]

[21] Shi, L.T.; Chen, L.; Ye, Z.B.; Zhou, W.; Zhang, J.; Yang, J.; Jin, J.B. Effect of polymer solution structure on displacement efficiency. Pet. Sci., 2012, 2, 230-235.

[http://dx.doi.org/10.1007/s12182-012-0203-z]

[22] Xia, H.F.; Wang, D.M.; Hou, J.R.; Xin, Q.G.; Liu, Y.K. Effect of viscoelasticity of polymer solution on oil displacement efficiency. J. Daqing Pet. Inst., 2002, 2(26), 109-111.

[23] Huang, B.; Fu, C.; Qu, S.C.; Yang, J. Effect of the polymer concentration and slug combination on oil displacement efficiency. Sci. Technol. Eng., 2011, 14(11), 3275-3277.

(C) Ma Wenguo; Licensee Bentham Open

This is an open access article licensed under the terms of the Creative Commons Attribution-Non-Commercial 4.0 International Public License (CC BY-NC 4.0) (https://creativecommons.org/licenses/by-nc/4.0/legalcode), which permits unrestricted, non-commercial use, distribution and reproduction in any medium, provided the work is properly cited. 